\title{
Degradation of various fruit juice anthocyanins by hydrogen peroxide
}

\author{
M. Özkan ${ }^{\mathrm{a}, *}$, A. Yemenicioğlu ${ }^{\mathrm{b}}$, B. Cemeroğlu ${ }^{\mathrm{a}}$ \\ a Department of Food Engineering, Faculty of Engineering, Ankara University, Diskapi Campus, Diskapi, 06110 Ankara, Turkey \\ b Department of Food Engineering, Faculty of Engineering, İmir Institute of Technology, Gaziosmanpaşa Bulvarl No. 16, \\ Çankaya, 35230 İzmir, Turkey
}

Received 9 June 2004; accepted 28 March 2005

\begin{abstract}
Degradation kinetics of anthocyanins was studied in sour cherry nectar, pomegranate and strawberry juices at high hydrogen peroxide $\left(\mathrm{H}_{2} \mathrm{O}_{2}\right)$ concentrations $\left(9.31-27.92 \mathrm{mmol} \mathrm{l}^{-1}\right)$ at $10-30{ }^{\circ} \mathrm{C}$ and in only sour cherry nectar at low $\mathrm{H}_{2} \mathrm{O}_{2}$ concentrations $\left(0.23-2.33 \mathrm{mmol}^{-1}\right)$ at $20^{\circ} \mathrm{C}$. Degradation of anthocyanins followed the first-order reaction kinetics. Sour cherry anthocyanins were the most resistant to $\mathrm{H}_{2} \mathrm{O}_{2}$, followed by pomegranate and strawberry anthocyanins. Degradation of anthocyanins was also studied in sour cherry nectar and pomegranate juice in the presence of ascorbic acid at 60 and $80 \mathrm{mg}^{-1}$ concentrations at $20^{\circ} \mathrm{C}$. At $80 \mathrm{mg}$ level, ascorbic acid significantly accelerated the degradation of anthocyanins in sour cherry nectar at 4.65 , 6.98 and $9.31 \mathrm{mmol}^{-1} \mathrm{H}_{2} \mathrm{O}_{2}$ concentrations. In contrast, ascorbic acid at both 60 and $80 \mathrm{mg}$ levels protected the anthocyanins from degradation by $\mathrm{H}_{2} \mathrm{O}_{2}$ in pomegranate juice.
\end{abstract}

(C) 2005 Elsevier Ltd. All rights reserved.

Keywords: Anthocyanins; Hydrogen peroxide; Ascorbic acid; Degradation; Kinetics; Fruit juices

\section{Introduction}

With FDA approval (1981), hydrogen peroxide $\left(\mathrm{H}_{2} \mathrm{O}_{2}\right)$ has found widespread use as a packaging sterilant in aseptic processing systems (Nelson, 1993). The sterilization of the packaging material used in aseptic systems is carried out by either dipping the packaging material into $\mathrm{H}_{2} \mathrm{O}_{2}$ bath or spraying $\mathrm{H}_{2} \mathrm{O}_{2}$ onto the polyethylene food contact surfaces. Although the excessive $\mathrm{H}_{2} \mathrm{O}_{2}$ is removed form the food contact surfaces by pressure roller in combination with scrapers and subsequent drying with sterile hot air at $180-205^{\circ} \mathrm{C}$ (Von Bockelmann \& Von Bockelmann, 1986), residues left on the packaging material or vapors generated during drying may sometimes get trapped inside the package

\footnotetext{
${ }^{*}$ Corresponding author. Tel.: +90 312317 0550x1146; fax: +90 312 3178711.

E-mail address: ozkanm@eng.ankara.edu.tr (M. Özkan).
}

upon sealing (Toledo, 1986). $\mathrm{H}_{2} \mathrm{O}_{2}$ may also derive from the aerobic degradation of ascorbic acid (Davídek, Velísek, \& Pokorny, 1990). Therefore, residues left inside packages, together with $\mathrm{H}_{2} \mathrm{O}_{2}$ formed from the degradation of ascorbic acid, may occasionally cause a quality loss in foods, especially fruit juices. The current FDA regulation limits residual $\mathrm{H}_{2} \mathrm{O}_{2}$ to $0.5 \mathrm{ppm}$ in finished food packages (Code of Federal Regulations, 2000).

Anthocyanins and ascorbic acid are the two important components adversely affected by $\mathrm{H}_{2} \mathrm{O}_{2}$ in fruit juices. The deleterious effect of $\mathrm{H}_{2} \mathrm{O}_{2}$ on anthocyanins was demonstrated in strawberry juice (Sondheimer \& Kertesz, 1952), and ascorbic acid in orange juice (Johnson \& Toledo, 1975) and in orange, grape and pomegranate juices as well as sour cherry nectar (Özkan, Kirca, \& Cemeroğlu, 2004). Sondheimer and Kertesz (1952) showed the extreme susceptibility of strawberry anthocyanins to $\mathrm{H}_{2} \mathrm{O}_{2}$. Johnson and Toledo (1975) reported a 2 -fold increase in the degradation rate of 
ascorbic acid when the aseptic chamber was pre-sterilized with $\mathrm{H}_{2} \mathrm{O}_{2}$ instead of steam.

Pomegranate and strawberry juices, and sour cherry nectar were selected in this study because of their high anthocyanin contents. In fact, anthocyanin contents were reported between 267 and $688 \mathrm{mg}^{-1}$ for sour cherry juice (Erbaş \& Cemeroğlu, 1992), 271-316 mg $1^{-1}$ for pomegranate juice (Bodur \& Yurdagel, 1986; Cemeroğlu \& Artık, 1990) and 176-445 $\mathrm{mg}^{-1}$ for strawberry juice (Pilando, Wrolstad, \& Heatherbell, 1985). In addition to its high anthocyanin content, sour cherry nectar is the most widely consumed anthocyanin containing fruit juice in Turkey and marketed as a clear nectar in carton-based laminated packages. The color loss in aseptically packaged sour cherry nectar has been brought to our attention by one of the major juice producers. Therefore, we conducted extensive research to show the adverse effects of $\mathrm{H}_{2} \mathrm{O}_{2}$ on the anthocyanins from sour cherry nectar, and pomegranate and strawberry juices (Özkan, Yemenicioğlu, Çıtak, \& Cemeroğlu, 2000; Özkan, Yemenicioğlu, Asefi, \& Cemeroğlu, 2002). Anthocyanin degradation was also studied in sour cherry nectar and pomegranate juice in the presence of added ascorbic acid (Özkan, 2002). These two juices were chosen because sour cherry (Herrmann, 1978) and pomegranate juices (Cemeroğlu, Artık, \& Erbaş, 1992) contain insignificant amounts of ascorbic acid. This article summarizes the results from the studies conducted in our laboratory.

\section{Materials and methods}

\subsection{Materials}

Pomegranates (Punica granatum L.) and fully ripened strawberries (Fragaria vesca L.) were purchased from a local market in Ankara. Fruits were brought to the fruit juice plant at Food Engineering Department and washed in cold tap water. The outer skins of pomegranates were hand-peeled. The juicy sacs from the fruit pericarp were separated by hand and pressed on a rack and cloth press (Bucher-Guyer, Niederweningen, Switzerland). The extracted juice was kept frozen at $-30^{\circ} \mathrm{C}$ in glass bottles. Before use, the juice was clarified at $4{ }^{\circ} \mathrm{C}$ overnight only with gelatin $(0.5 \%)$ and then filtered.

Strawberries were homogenized in a high speed blender. The homogenate was depectinized with the enzyme Pectinex Ultra SP-L (Novo Nordisk, Dittingen, Switzerland) at $50{ }^{\circ} \mathrm{C}$ for $2 \mathrm{~h}$ and filtered through seven layers of muslin cloth and then filter paper. The filtered juice was kept frozen at $-30{ }^{\circ} \mathrm{C}$ in glass bottles until used for analysis. Sour cherry (Prunus cerasus L.) nectar was obtained in $200-\mathrm{ml}$ bottles directly from the commercial production of fruit juice plant at Food Engineering Department.

\subsection{Sample preparation and absorption spectra}

The juice samples were diluted with distilled water to give an absorbance reading between 0.6 and 0.8 units and filtered again prior to degradation studies. The absorption spectra were scanned from 350 to $700 \mathrm{~nm}$ with a Unicam UV2-100 spectrophotometer (Unicam, Cambridge, England), using 1-cm quartz cuvettes. The wavelengths of maximum absorptions were 499, 512 and $515 \mathrm{~nm}$ for strawberry, sour cherry and pomegranate anthocyanins, respectively. All absorbance readings were made against distilled water as a blank. The $\mathrm{pH}$ of diluted pomegranate, strawberry and sour cherry juices at $20^{\circ} \mathrm{C}$ was $3.32,3.40$ and 3.50 , respectively.

\subsection{Degradation studies}

The effects of various $\mathrm{H}_{2} \mathrm{O}_{2}$ concentrations on the anthocyanins of sour cherry, pomegranate and strawberry juices were studied at 10,20 and $30^{\circ} \mathrm{C}$. The diluted juice samples were allowed to reach the required temperature in a Sanyo MIR 153 model refrigerated incubator (Sanyo, Gunma, Japan). Then, the predetermined volumes of diluted $\mathrm{H}_{2} \mathrm{O}_{2}$ solutions (prepared from $35 \%$ stock $\mathrm{H}_{2} \mathrm{O}_{2}$ solution) were added rapidly to the juice samples to obtain final $\mathrm{H}_{2} \mathrm{O}_{2}$ concentrations of $9.31,13.96,18.60,23.27$ and $27.92 \mathrm{mmol} \mathrm{l}^{-1}$. The absorbance of the sample solutions was measured periodically. The zero-time absorbance values were determined by preparing the samples with the same amount of distilled water instead of $\mathrm{H}_{2} \mathrm{O}_{2}$. At $10-30{ }^{\circ} \mathrm{C}$, the change in absorbance of the sample solution containing no $\mathrm{H}_{2} \mathrm{O}_{2}$ was insignificant over time. The anthocyanin retention for each time period was calculated as percentage of zero-time absorbance readings, taken as 100\% retention. Hydrogen peroxide was purchased from Merck Co. (Darmstad, Germany).

The degradation of anthocyanins was also studied in only sour cherry nectar at low $\mathrm{H}_{2} \mathrm{O}_{2}$ concentrations $\left(0.23-2.33 \mathrm{mmol}^{-1}\right)$ at $20^{\circ} \mathrm{C}$. Finally, degradation of anthocyanins was studied in the presence of 60 and $80 \mathrm{mg}^{-1}$ ascorbic acid at 4.65, 6.98 and $9.31 \mathrm{mmol}^{-1}$ $\mathrm{H}_{2} \mathrm{O}_{2}$ concentrations in sour cherry nectar and pomegranate juice.

\section{Results and discussion}

\subsection{Degradation mechanism}

The decomposition of $\mathrm{H}_{2} \mathrm{O}_{2}$ in an aqueous solution occurs in two ways: (1) dissociation and $(2,3)$ homolytic cleavage of $\mathrm{O}-\mathrm{H}$ or $\mathrm{O}-\mathrm{O}$ bonds. These reactions leads to the formation of highly reactive products: perhydroxyl anion $\left(\mathrm{HOO}^{-}\right)$, and perhydroxyl $(\cdot \mathrm{OOH})$ and hydroxyl ('OH) radicals (De, Chaudhuri, \& Bhattacharjee, 1999). 


$$
\begin{aligned}
& \mathrm{H}_{2} \mathrm{O}_{2} \rightarrow \mathrm{H}^{+}+\mathrm{HOO}^{-} \quad K=1.55 \times 10^{-12} \\
& \mathrm{HOOH} \rightarrow{ }^{\circ} \mathrm{OOH}+{ }^{\cdot} \mathrm{H} \\
& \mathrm{HOOH} \rightarrow 2^{\cdot} \mathrm{OH}
\end{aligned}
$$

The decomposition and dissociation products of $\mathrm{H}_{2} \mathrm{O}_{2}$ have been shown to be responsible for the oxidation and subsequent degradation of phenolic compounds, including anthocyanins (Sapers \& Simmons, 1998; Sapers, Miller, Choi, \& Cooke, 1999). In fact, $\mathrm{De}$ et al. (1999) found that 'OH radical is the main reactive species to cleave the benzene ring in phenolic compounds and degrade the substrate eventually into $\mathrm{CO}_{2}$ and $\mathrm{H}_{2} \mathrm{O}$. Von Elbe and Schwartz (1996) reported that quinones, formed by the oxidation of phenols, also have deleterious effects on anthocyanins. Thus, two factors can primarily affect the degradation of anthocyanins by $\mathrm{H}_{2} \mathrm{O}_{2}$ in fruit juices which generally contain copious amounts of phenolic compounds: (1) the amount of free radicals and $\mathrm{HOO}^{-}$anion formed by the decomposition and dissociation of $\mathrm{H}_{2} \mathrm{O}_{2}$, respectively; (2) the amount of quinones formed by the $\mathrm{H}_{2} \mathrm{O}_{2}$-catalyzed oxidation of phenolic compounds.

Sondheimer and Kertesz (1952) were among the first to investigate the kinetics of anthocyanin degradation by $\mathrm{H}_{2} \mathrm{O}_{2}$ in both strawberry juice and pure solutions of the major strawberry anthocyanin (pelargonidine-3glucoside). According to these workers, the oxidative degradation of anthocyanins occurs in two steps: an initial reversible reaction with the formation of anthocyanin- $\mathrm{H}_{2} \mathrm{O}_{2}$ adduct, followed by a slower irreversible one. $\mathrm{H}_{2} \mathrm{O}_{2}$ or its decomposition products cleaves the neighboring carbon-carbon bond at the C-2 and C-3 positions of anthocyanins to form colorless malvones (Coultate, 1989).

\subsection{Degradation kinetics}

The degradation of anthocyanins by $\mathrm{H}_{2} \mathrm{O}_{2}$ was fitted to a first-order kinetic model (Fig. 1). The reaction rate constant $(k)$ and half-life $\left(t_{1 / 2}\right)$, the time needed for $50 \%$ degradation of anthocyanins at a given $\mathrm{H}_{2} \mathrm{O}_{2}$ concentration and temperature, were calculated by the following equations:

$$
\begin{aligned}
& \ln \left(A_{t} / A_{0}\right)=-k \times t, \\
& t_{1 / 2}=-\ln 0.5 / k,
\end{aligned}
$$

where $A_{0}$ is the initial absorbance of diluted fruit juice and $A_{t}$ is the absorbance value after $t$ min incubation at a given temperature.

The effect of $\mathrm{H}_{2} \mathrm{O}_{2}$ on anthocyanins was studied at both high $\mathrm{H}_{2} \mathrm{O}_{2}$ concentrations (9.31-27.92 $\mathrm{mmol}^{-1}$ ) at $10-30{ }^{\circ} \mathrm{C}$ and low $\mathrm{H}_{2} \mathrm{O}_{2}$ concentrations $(0.23-$ $2.33 \mathrm{mmol}^{-1}$ ) at $20^{\circ} \mathrm{C}$. At high $\mathrm{H}_{2} \mathrm{O}_{2}$ concentrations, strawberry anthocyanins showed the highest susceptibility to $\mathrm{H}_{2} \mathrm{O}_{2}$, followed by pomegranate and sour cherry

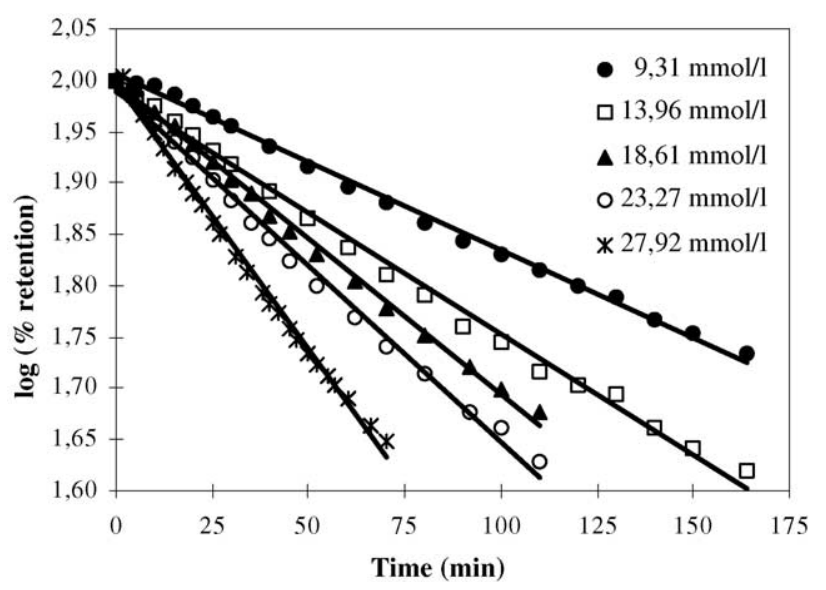

Fig. 1. Degradation of pomegranate juice anthocyanins at various $\mathrm{H}_{2} \mathrm{O}_{2}$ concentrations and $20{ }^{\circ} \mathrm{C}$.

anthocyanins, as indicated by the highest $k$ and the lowest $t_{1 / 2}$ values (Table 1 ). Sondheimer and Kertesz (1952) reported the $t_{1 / 2}$ values for anthocyanins in strawberry juice as 6, 9 and $13 \mathrm{~min}$ for $77.4,10.7$ and $2.4 \mathrm{mmol} \mathrm{l}^{-1}$ $\mathrm{H}_{2} \mathrm{O}_{2}$ concentrations at $20^{\circ} \mathrm{C}$, respectively. Compared to our $t_{1 / 2}$ values for strawberry anthocyanins, their $t_{1 / 2}$ values were much lower. These results clearly indicate that, in the production of anthocyanin-rich fruit juices which have higher susceptibility to $\mathrm{H}_{2} \mathrm{O}_{2}$, the removal of $\mathrm{H}_{2} \mathrm{O}_{2}$ from juice contact surfaces of aseptic packages should be controlled very carefully to minimize anthocyanin losses.

The different susceptibilities of anthocyanins to $\mathrm{H}_{2} \mathrm{O}_{2}$ were also reported by Sapers and Simmons (1998). These workers observed much faster bleaching of raspberry and strawberry anthocyanins by $\mathrm{H}_{2} \mathrm{O}_{2}$, as compared to sweet cherry anthocyanins. Although our results correlate well with those of Sapers and Simmons (1998) who applied $\mathrm{H}_{2} \mathrm{O}_{2}$ for surface sterilization of these fruits, while we added $\mathrm{H}_{2} \mathrm{O}_{2}$ directly to the fruit juices where $\mathrm{H}_{2} \mathrm{O}_{2}$ and anthocyanins reacted easily. The protective skins of cherries probably prevented $\mathrm{H}_{2} \mathrm{O}_{2}$ to diffuse freely to the interior of fruits.

The high reactivity to $\mathrm{H}_{2} \mathrm{O}_{2}$ suggests the greater antioxidant potential of strawberry juice anthocyanins against reactive oxygen species (ROS). The different susceptibilities of fruit juice anthocyanins to $\mathrm{H}_{2} \mathrm{O}_{2}$ may be due to their varying anthocyanidin composition. The cyanidins were reported as the main anthocyanidins in pomegranate seed coats (Du, Wang, \& Francis, 1975) and sour cherries (Dekazos, 1970), whereas the pelargonidins were reported as the major ones in strawberries (Fuleki, 1969). Thus, higher resistance of sour cherry and pomegranate juice anthocyanins to $\mathrm{H}_{2} \mathrm{O}_{2}$ may be attributed to the presence of cyanidins in these juices. Moreover, the quinones, formed by the $\mathrm{H}_{2} \mathrm{O}_{2}$-catalyzed oxidation of phenolic compounds, can also contribute to the degradation of anthocyanins. Therefore, the 
Table 1

Effect of temperature on the degradation of sour cherry, pomegranate and strawberry anthocyanins at various $\mathrm{H}_{2} \mathrm{O}_{2}$ concentrations

\begin{tabular}{|c|c|c|c|c|c|c|c|}
\hline \multirow{2}{*}{$\begin{array}{l}\mathrm{H}_{2} \mathrm{O}_{2} \text { concentration } \\
\left(\mathrm{mmol}^{-1}\right)\end{array}$} & \multirow{2}{*}{$\begin{array}{l}\text { Temperature } \\
\left({ }^{\circ} \mathrm{C}\right)\end{array}$} & \multicolumn{2}{|l|}{ Sour cherry } & \multicolumn{2}{|l|}{ Pomegranate } & \multicolumn{2}{|l|}{ Strawberry } \\
\hline & & $k^{\mathrm{a}}\left(10^{3} \times \min ^{-1}\right)$ & $t_{1 / 2}(\mathrm{~h})$ & $k^{\mathrm{a}}\left(10^{3} \times \min ^{-1}\right)$ & $t_{1 / 2}(\mathrm{~h})$ & $k^{\mathrm{a}}\left(10^{3} \times \min ^{-1}\right)$ & $t_{1 / 2}(\mathrm{~h})$ \\
\hline \multirow[t]{3}{*}{9.31} & 10 & 1.54 & 7.5 & 1.80 & 6.4 & 2.37 & 4.9 \\
\hline & 20 & 2.86 & 4.0 & 3.92 & 2.9 & 4.08 & 2.8 \\
\hline & 30 & 5.02 & 2.3 & 7.14 & 1.6 & 7.19 & 1.6 \\
\hline \multirow[t]{3}{*}{13.96} & 10 & 2.49 & 4.6 & 2.42 & 4.8 & 3.11 & 3.7 \\
\hline & 20 & 4.49 & 2.6 & 5.46 & 2.1 & 5.71 & 2.0 \\
\hline & 30 & 7.97 & 1.4 & 9.72 & 1.2 & 9.90 & 1.2 \\
\hline \multirow[t]{3}{*}{8.61} & 10 & 2.72 & 4.2 & 3.62 & 3.2 & 3.94 & 2.9 \\
\hline & 20 & 5.57 & 2.1 & 7.00 & 1.7 & 7.85 & 1.5 \\
\hline & 30 & 10.36 & 1.1 & 14.46 & 0.8 & 14.07 & 0.8 \\
\hline \multirow[t]{3}{*}{23.27} & 10 & 3.96 & 2.9 & 4.38 & 2.6 & 4.97 & 2.3 \\
\hline & 20 & 6.96 & 1.7 & 7.88 & 1.5 & 9.70 & 1.2 \\
\hline & 30 & 13.50 & 0.9 & 16.72 & 0.7 & 18.40 & 0.6 \\
\hline \multirow[t]{3}{*}{27.92} & 10 & 5.00 & 2.3 & 5.09 & 2.3 & 5.50 & 2.1 \\
\hline & 20 & 9.40 & 1.2 & 12.02 & 1.0 & 12.23 & 0.9 \\
\hline & 30 & 15.25 & 0.8 & 21.19 & 0.5 & 19.46 & 0.6 \\
\hline
\end{tabular}

${ }^{a}$ Determination coefficients for $k$ values are over 0.99 .

differences in the amount and composition of phenolics in sour cherry, pomegranate and strawberry juices could also have affected the degradation rate of anthocyanins. Furthermore, the high amount of ascorbic acid in strawberry juice may have also contributed to the degradation of anthocyanins. In fact, the adverse effects of ascorbic acid on anthocyanins have been shown in strawberry juice (Sondheimer \& Kertesz, 1953) and model systems containing strawberry anthocyanins (Markakis, Livingston, \& Fellers, 1957). Contrary to strawberry juice, both sour cherry (Herrmann, 1978) and pomegranate juices (Cemeroğlu et al., 1992) contain insignificant amounts of ascorbic acid.

The effect of low $\mathrm{H}_{2} \mathrm{O}_{2}$ concentrations $(0.23$ $2.33 \mathrm{mmol}^{-1}$ ) on anthocyanin degradation was studied only in sour cherry nectar at $20^{\circ} \mathrm{C}$. At these $\mathrm{H}_{2} \mathrm{O}_{2}$ concentrations, the $t_{1 / 2}$ values varied between 111 and $20 \mathrm{~h}$, respectively (Table 2). A quadratic relationship was obtained between $k$ and $\mathrm{H}_{2} \mathrm{O}_{2}$ concentrations and the equation for this relationship is expressed as

Table 2

Effect of different $\mathrm{H}_{2} \mathrm{O}_{2}$ concentrations on the degradation of sour cherry anthocyanins at $20^{\circ} \mathrm{C}$

\begin{tabular}{lcc}
\hline $\mathrm{H}_{2} \mathrm{O}_{2}$ concentration $\left(\mathrm{mmol} \mathrm{l}^{-1}\right)$ & $k\left(10^{3} \times \mathrm{h}^{-1}\right)$ & $t_{1 / 2}(\mathrm{~h})$ \\
\hline 0.23 & $6.22(0.982)^{\mathrm{a}}$ & 111 \\
0.47 & $10.59(0.975)$ & 65 \\
0.70 & $15.56(0.969)$ & 45 \\
0.93 & $18.09(0.981)$ & 38 \\
1.16 & $20.96(0.990)$ & 33 \\
2.33 & $34.81(0.982)$ & 20 \\
\hline
\end{tabular}

${ }^{\mathrm{a}}$ Number in brackets is the determination coefficient.
$k=-0.0031\left[\mathrm{H}_{2} \mathrm{O}_{2}\right]^{2}+0.0218\left[\mathrm{H}_{2} \mathrm{O}_{2}\right]+0.0008$

$\left(R^{2}=0.996\right)$.

If one places $0.0147 \mathrm{mmol}^{-1}(0.5 \mathrm{ppm})$ in the above equation, which is the maximum allowed level of $\mathrm{H}_{2} \mathrm{O}_{2}$ in the finished food packages by FDA, a $k$ of $1.12 \times 10^{-3} \mathrm{~h}^{-1}$ and $t_{1 / 2}$ of 26 days at $20^{\circ} \mathrm{C}$ are calculated. Such values indicate that fruit juice anthocyanins may be degraded even at very low $\mathrm{H}_{2} \mathrm{O}_{2}$ concentrations.

\subsection{Effect of ascorbic acid concentration}

In sour cherry nectar and pomegranate juice, the stability of anthocyanins to $\mathrm{H}_{2} \mathrm{O}_{2} \quad(4.65,6.98$ and $9.31 \mathrm{mmol}^{-1}$ ) was also studied at 60 and $80 \mathrm{mg} \mathrm{l}^{-1}$ ascorbic acid concentrations at $20^{\circ} \mathrm{C}$. The stability of anthocyanins was higher in samples containing both ascorbic acid $\left(60 \mathrm{mg}^{-1}\right)$ and $\mathrm{H}_{2} \mathrm{O}_{2}$ than in samples containing only $\mathrm{H}_{2} \mathrm{O}_{2}$. However, ascorbic acid at $80 \mathrm{mg}$ level markedly increased the degradation of anthocyanins in sour cherry nectar samples in the presence of $\mathrm{H}_{2} \mathrm{O}_{2}$ (Fig. 2). For example, the $t_{1 / 2}$ values at $60 \mathrm{mg}$ ascorbic acid level for sour cherry anthocyanins were over $450 \mathrm{~min}$ for all three $\mathrm{H}_{2} \mathrm{O}_{2}$ concentrations studied, whereas the $t_{1 / 2}$ values decreased sharply, down to $8 \mathrm{~min}$, at $80 \mathrm{mg}$ level (Table 3). Similarly, Freedman and Francis (1984) found that the anthocyanins in blackberry jelly showed little change during 32 weeks of storage at both 0 and $35 \mathrm{mg}$ ascorbic acid in $100 \mathrm{ml}$ jelly. On the contrary, raising ascorbic acid level to $70 \mathrm{mg}$ resulted in a lighter colored product, as indicated by the shift in the hue values from "red" region to "yellow" region. 


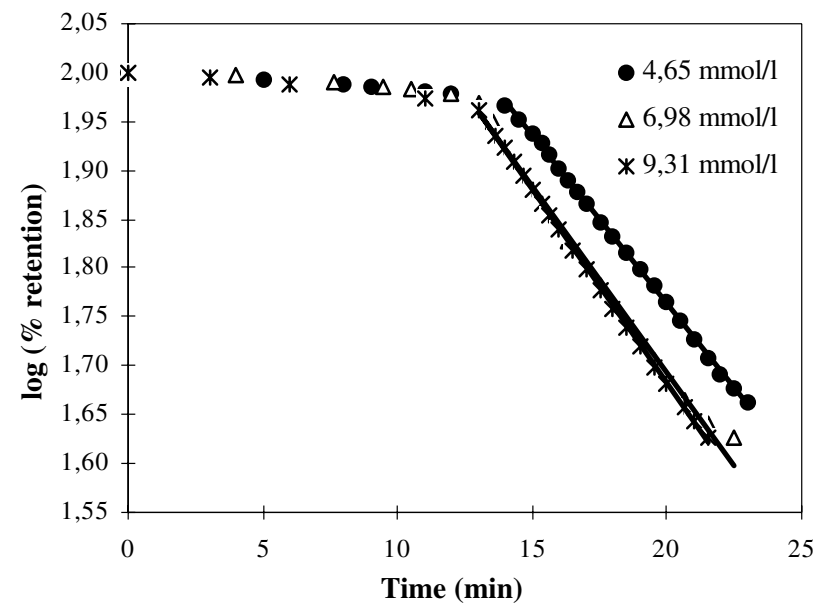

Fig. 2. Degradation of sour cherry anthocyanins at various $\mathrm{H}_{2} \mathrm{O}_{2}$ concentrations in the presence of added ascorbic acid $\left(80 \mathrm{mg} \mathrm{l}^{-1}\right)$ at $20^{\circ} \mathrm{C}$.

The accelerated degradation of anthocyanins in the presence of both $\mathrm{H}_{2} \mathrm{O}_{2}$ and ascorbic acid can be attributed to the degradation products of ascorbic acid. In fact, Sondheimer and Kertesz (1953) showed the maximum loss of strawberry anthocyanins under conditions most favorable to ascorbic acid degradation. This indicates that the degradation products of ascorbic acid, not ascorbic acid itself, are responsible for the anthocyanin degradation (Jackman, Yada, Tung, \& Speers, 1987). Of the degradation products, dehydroascorbic acid, furfurals and $\mathrm{H}_{2} \mathrm{O}_{2}$ were thought to be responsible for the degradation of anthocyanins (Meschter, 1953). The combined presence of $\mathrm{O}_{2}$ and ascorbic acid has also been demonstrated to have a synergistic effect on anthocyanin degradation (Markakis et al., 1957). Iversen (1999) found that the degradation rate of anthocyanins in black currant nectar was 3-4 times faster than that of ascorbic acid depending on the storage in dark or daylight, respectively. The authors concluded that the loss of anthocyanins is favored for the protection of ascorbic acid and they attributed the ascorbic acid protecting effect of anthocyanins to the conversion of ascor- bic acid radicals into ascorbic acid by oxidizing one molecule anthocyanins to its stabilized radical form.

\subsection{Temperature dependence}

The temperature dependence of anthocyanin degradation by $\mathrm{H}_{2} \mathrm{O}_{2}$ was determined by calculating activation energies $\left(E_{\mathrm{a}}\right)$ and temperature quotients $\left(Q_{10}\right)$ from the following equations:

$k=k_{0} \times \mathrm{e}^{-E_{\mathrm{a}} / R T}$,
$Q_{10}=k_{(T+10)} / k_{(T)}$.

At 9.31-27.92 $\mathrm{mmol}^{-1} \mathrm{H}_{2} \mathrm{O}_{2}$ concentrations and 10$30^{\circ} \mathrm{C}$, the $E_{\mathrm{a}}$ values varied between 39.3 and $46.4 \mathrm{~kJ} \mathrm{~mol}^{-1}$ for strawberry, $39.7-47.7 \mathrm{~kJ} \mathrm{~mol}^{-1}$ for sour cherry and $47.7-51.0 \mathrm{~kJ} \mathrm{~mol}^{-1}$ for pomegranate anthocyanins (Özkan et al., 2002). At the same concentration and temperature ranges, the respective $Q_{10}$ values were between $1.59-2.22,1.62-2.05$ and $1.76-2.36$ for strawberry, sour cherry and pomegranate anthocyanins, respectively. Higher $E_{\mathrm{a}}$ and $Q_{10}$ values indicated the higher temperature dependence for the degradation of pomegranate juice anthocyanins by $\mathrm{H}_{2} \mathrm{O}_{2}$.

In long-term storage, the cold storage temperatures prevent the degradation of anthocyanins. In fact, Cemeroğlu, Velioğlu, and Iş̧k (1994) showed that storing sour cherry concentrate at $5^{\circ} \mathrm{C}$ rather than $20^{\circ} \mathrm{C}$ resulted in an almost 10 -fold increase in the $t_{1 / 2}$ values of sour cherry anthocyanins, 38-356 days. Similarly, $t_{1 / 2}$ values of anthocyanins for aseptically packed cranberry juice cocktail were reported to be 210 days at $-18{ }^{\circ} \mathrm{C}, 112$ days at $21^{\circ} \mathrm{C}$ and 86 days at $36^{\circ} \mathrm{C}$ (Toledo, 1986). The effect of storage temperature was found to be more pronounced for the anthocyanins of aseptically packaged blueberry juice, which has a $Q_{10}$ value of 2.4 at $25-38{ }^{\circ} \mathrm{C}$ as compared to cranberry juice anthocyanins with a $Q_{10}$ value of 1.2 at $21-36^{\circ} \mathrm{C}$ (Toledo, 1986).

The plots of $k$ vs $\mathrm{H}_{2} \mathrm{O}_{2}$ concentrations at different temperatures showed that anthocyanin degradation increased as the temperature and $\mathrm{H}_{2} \mathrm{O}_{2}$ concentration increased in all three samples (Özkan et al., 2002). Thus,

Table 3

Effect of $\mathrm{H}_{2} \mathrm{O}_{2}$ and ascorbic acid concentrations on anthocyanins from sour cherry nectar and pomegranate juice at $20^{\circ} \mathrm{C}$

\begin{tabular}{|c|c|c|c|c|c|}
\hline \multirow{2}{*}{$\begin{array}{l}\mathrm{H}_{2} \mathrm{O}_{2} \text { concentration } \\
\left(\mathrm{mmol} \mathrm{l}^{-1}\right)\end{array}$} & \multirow{2}{*}{$\begin{array}{l}\text { Ascorbic acid concentration } \\
\left(\mathrm{mg} \mathrm{l}^{-1}\right)\end{array}$} & \multicolumn{2}{|c|}{$k^{\mathrm{a}}\left(10^{3} \times \min ^{-1}\right)$} & \multicolumn{2}{|l|}{$t_{1 / 2}(\min )$} \\
\hline & & Sour cherry & Pomegranate & Sour cherry & Pomegranate \\
\hline 4.65 & 0 & 1.66 & 2.14 & 418 & 324 \\
\hline 6.98 & 0 & 2.49 & 3.13 & 279 & 221 \\
\hline 9.31 & 0 & 2.86 & 4.01 & 243 & 173 \\
\hline 4.65 & 60 & 0.019 & 1.52 & 450 & 456 \\
\hline 6.98 & 60 & 0.026 & 2.14 & 450 & 324 \\
\hline 9.31 & 60 & 0.038 & 2.79 & 450 & 249 \\
\hline 4.65 & 80 & 79.5 & 1.66 & 9 & 418 \\
\hline 6.98 & 80 & 87.5 & 2.40 & 8 & 289 \\
\hline 9.31 & 80 & 91.5 & 3.11 & 8 & 223 \\
\hline
\end{tabular}

${ }^{\text {a }}$ Determination coefficients for $k$ values are over 0.99 . 
greater anthocyanin losses should be expected as residual $\mathrm{H}_{2} \mathrm{O}_{2}$ concentration and storage temperature increase in aseptically packaged fruit juices.

\section{Conclusions}

Anthocyanins from various fruit juices were found to be very susceptible to $\mathrm{H}_{2} \mathrm{O}_{2}$. A rapid degradation may occur even at $\mathrm{H}_{2} \mathrm{O}_{2}$ concentrations as low as FDA limit. Therefore, aseptic systems should be frequently controlled to ensure the effective removal of residual $\mathrm{H}_{2} \mathrm{O}_{2}$ from the food contact surfaces. Since the rate of anthocyanin degradation by $\mathrm{H}_{2} \mathrm{O}_{2}$ is highly dependent on temperature, cold storage of aseptically packed anthocyanin-rich fruit juices is strongly recommended to minimize anthocyanin degradation by residual $\mathrm{H}_{2} \mathrm{O}_{2}$ and temperature. Compared to pomegranate and sour cherry anthocyanins, strawberry anthocyanins were much more susceptible to $\mathrm{H}_{2} \mathrm{O}_{2}$. At $60 \mathrm{mg}^{-1}$ ascorbic acid, the susceptibility of pomegranate and sour cherry anthocyanins to $\mathrm{H}_{2} \mathrm{O}_{2}$ reduced. However, the degradation of anthocyanins in sour cherry nectar markedly increased at $80 \mathrm{mg}$ ascorbic acid level. Therefore, the fortification of aseptically packed anthocyanin-rich fruit juices with ascorbic acid should be avoided or carried out very carefully.

\section{Acknowledgement}

This work was funded by "Ankara University Research Funds,” Turkey (Grant \# 98.11.12.01).

\section{References}

Bodur, J., \& Yurdagel, Ü. (1986). Nar konsantresinin donmuş ve kimyasal katkılanmış olarak soğukta depolanması sırasında meydana gelen değişmeler üzerinde bir araştırma [Quality changes of pomegranate juice concentrate during cold and frozen storage]. Ege Üniversitesi Mühendislik Fakültesi Dergisi, 4(2), 11-26.

Cemeroğlu, B., \& Artık, N. (1990). Isıl işlem ve depolama koşullarının nar antosiyaninleri üzerine etkisi [Effect of thermal process and storage conditions on anthocyanins from pomegranate]. Glda Dergisi, 15(1), 13-19.

Cemeroğlu, B., Artık, N., \& Erbaş, S. (1992). Gewinnung von Granatapfelsaft und seine Zusammensetzung. Flüssiges Obst, 59(6), 335-340.

Cemeroğlu, B., Velioğlu, S., \& Işık, S. (1994). Degradation kinetics of anthocyanins in sour cherry juice and concentrate. Journal of Food Science, 59(6), 1216-1218.

Code of Federal Regulations. (2000). Direct food substances affirmed as generally recognized as safe. 21 CFR 184.1366. Office of the Federal Register. Washington, DC: US Government Printing Office.

Coultate, T. P. (1989). Food: The chemistry of its components (2nd ed., pp. 126-158). London: Royal Society of Chemistry.

Davídek, J., Velísek, J., \& Pokorny, J. (1990). Chemical changes during food processing (pp. 302-378). New York: Marcel Dekker.
De, A. K., Chaudhuri, B., \& Bhattacharjee, S. (1999). A kinetic study of the oxidation of phenol, $o$-chlorophenol and catechol by hydrogen peroxide between $298 \mathrm{~K}$ and $333 \mathrm{~K}$ : The effect of $\mathrm{pH}$, temperature and ratio of oxidant to substrate. Journal of Chemical Technology and Biotechnology, 74(2), 162-168.

Dekazos, E. D. (1970). Anthocyanin pigments in red tart cherries. Journal of Food Science, 35(3), 237-241.

Du, C. T., Wang, P. L., \& Francis, F. J. (1975). Anthocyanins of pomegranate, Punica granatum. Journal of Food Science, 40(2), $417-418$.

Erbaş, S., \& Cemeroğlu, B. (1992). Erzeugung und verarbeitung von sauerkirschen in der Türkei. Flüssiges Obst, 59(4), 170175.

Freedman, L., \& Francis, F. J. (1984). Effect of ascorbic acid on color of jellies. Journal of Food Science, 49(4), 12121213.

Fuleki, T. (1969). The anthocyanins of strawberry, rhubarb, radish and onion. Journal of Food Science, 34(4), 365-369.

Herrmann, K. (1978). Chemische zusammensetzung von obst und fruchtsäften einschließlich wichtiger gemüsesäfte sowie deren ernährungsphysiologische bedeutung. In V. U. Schobinger (Ed.), Handbuch der getränketechnologie: Frucht-und gemüsesäfte (pp. 32-79). Stuttgart: Eugen Ulmer GmbH, Co..

Iversen, C. K. (1999). Black currant nectar: Effect of processing and storage on anthocyanin and ascorbic acid content. Journal of Food Science, 64(1), 37-41.

Jackman, R. L., Yada, R. Y., Tung, M. A., \& Speers, R. A. (1987). Anthocyanins as food colorants - A review. Journal of Food Biochemistry, 11, 201-247.

Johnson, R. L., \& Toledo, R. T. (1975). Storage stability of $55^{\circ}$ Brix orange juice concentrate aseptically packaged in plastic and glass containers. Journal of Food Science, 40(2), 433-434.

Markakis, P., Livingston, G. E., \& Fellers, C. R. (1957). Quantitative aspects of strawberry pigment degradation. Food Research, 22(2), $117-130$

Meschter, E. E. (1953). Fruit color loss: Effects of carbohydrates and other factors on strawberry products. Journal of Agricultural and Food Chemistry, 1(8), 574-579.

Nelson, P. E. (1993). Introduction. In J. V. Chambers \& P. E. Nelson (Eds.), Principles of aseptic processing and packaging (2nd ed.) (pp. 1-2). Washington: Food Processors Institute.

Özkan, M. (2002). Degradation of anthocyanins in sour cherry and pomegranate juices by hydrogen peroxide in the presence of added ascorbic acid. Food Chemistry, 78(4), 499-504.

Özkan, M., Yemenicioğlu, A., Asefi, N., \& Cemeroğlu, B. (2002). Degradation kinetics of anthocyanins from sour cherry, pomegranate and strawberry juices by hydrogen peroxide. Journal of Food Science, 67(2), 525-529.

Özkan, M., Yemenicioğlu, A., Çıtak, B., \& Cemeroğlu, B. (2000). Effect of hydrogen peroxide on sour cherry anthocyanins. Journal of Food Quality, 23(4), 421-428.

Özkan, M., Kırca, A., \& Cemeroğlu, B. (2004). Effects of hydrogen peroxide on the stability of ascorbic acid during storage in various fruit juices. Food Chemistry, 88(4), 591-597.

Pilando, L. S., Wrolstad, R. E., \& Heatherbell, D. A. (1985). Influence of fruit composition, maturity and mold contamination on the color and appearance of strawberry wine. Journal of Food Science, 50(4), 1121-1125.

Sapers, G. M., \& Simmons, G. F. (1998). Hydrogen peroxide disinfection of minimally processed fruits and vegetables. Food Technology, 52(2), 48-52.

Sapers, G. M., Miller, R. L., Choi, S. W., \& Cooke, P. H. (1999). Structure and composition of mushrooms as affected by hydrogen peroxide wash. Journal of Food Science, 64(5), 889-892.

Sondheimer, E., \& Kertesz, Z. I. (1952). The kinetics of the oxidation of strawberry anthocyanin by hydrogen peroxide. Food Research, 17(3), 288-298. 
Sondheimer, E., \& Kertesz, Z. I. (1953). Participation of ascorbic acid in the destruction of anthocyanin in strawberry juice and model systems. Food Research, 18(5), 475-479.

Toledo, R. T. (1986). Postprocessing changes in aseptically packed beverages. Journal of Agricultural and Food Chemistry, 34(3), 405-408.
Von Bockelmann, B. A. H., \& Von Bockelmann, I. L. I. (1986). Aseptic packaging of liquid food products: A literature review. Journal of Agricultural and Food Chemistry, 34(3), 384-392.

Von Elbe, J. H., \& Schwartz, S. J. (1996). Colorants. In O. R. Fennema (Ed.), Food chemistry (3rd ed.) (pp. 651-722). New York: Marcel Dekker. 